Article

\title{
Phenolic Acids from Lycium barbarum Leaves: In Vitro and In Silico Studies of the Inhibitory Activity against Porcine Pancreatic $\alpha$-Amylase
}

\author{
Luna Pollini ${ }^{1}{ }^{\circledR}$, Alessandra Riccio ${ }^{2}$, Cristina Juan ${ }^{3}$, Carmela Tringaniello ${ }^{1} \mathbb{(}$, Federica Ianni ${ }^{1}$,

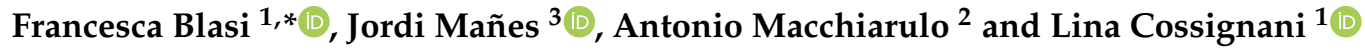 \\ 1 Food Science and Nutrition Section, Department of Pharmaceutical Sciences, University of Perugia, \\ 06126 Perugia, Italy; luna.pollini@studenti.unipg.it (L.P.); carmela.tringaniello@unipg.it (C.T.); \\ federica.ianni@unipg.it (F.I.); lina.cossignani@unipg.it (L.C.) \\ 2 Chemistry and Technology of Drug Section, Department of Pharmaceutical Sciences, University of Perugia, \\ 06123 Perugia, Italy; alessandra.riccio1@studenti.unipg.it (A.R.); antonio.macchiarulo@unipg.it (A.M.) \\ 3 Laboratory of Food Chemistry and Toxicology, Faculty of Pharmacy, University of Valencia, Av. Vicent \\ Andrés Estellés s/n, 46100 Burjassot, Spain; cristina.juan@uv.es (C.J.); jordi.manes@uv.es (J.M.) \\ * Correspondence: francesca.blasi@unipg.it; Tel.: +39-075-585-7954
}

Received: 4 September 2020; Accepted: 27 October 2020; Published: 30 October 2020

\begin{abstract}
Nowadays, bioactive compounds from vegetable food and waste are of great interest for their inhibitory potential against digestive enzymes. In the present study, the inhibitory activity of methanolic extract from Lycium barbarum leaves on porcine pancreas $\alpha$-amylase has been studied. The $\alpha$-amylase inhibitory activity of the constituent phenolic acids was also investigated. The leaves were extracted by ultrasound-assisted method, one of the most efficient techniques for bioactive extraction from plant materials, and then the phenolic acids were identified by Accurate-Mass Quadrupole Time-of-Flight (Q-TOF) Liquid Chromatography/Mass Spectrometry (LC/MS). Chlorogenic and salicylic acids were the most abundant phenolic acids in L. barbarum leaf extract. The inhibitory effect against $\alpha$-amylase, determined for individual compounds by in vitro assay, was higher for chlorogenic, salicylic, and caffeic acids. L. barbarum leaf extract showed an appreciable $\alpha$-amylase inhibitory effect in a concentration-dependent manner. Docking studies of the considered phenolic acids into the active site of $\alpha$-amylase suggested a conserved binding mode that is mainly stabilized through $\mathrm{H}$-bonds and $\pi-\pi$ stacking interactions.
\end{abstract}

Keywords: hypoglycaemic activity; molecular docking; goji leaves; bioactives; antioxidant activity; food waste; UAE

\section{Introduction}

Despite the large number of synthetic pharmaceuticals, interest into natural products is increasing. The agricultural field offers a great opportunity thanks to the large quantities of byproducts of plant food processing, a promising source of biologically active compounds. In this context, food waste such as leaves are a cheap and available source of naturally-occurring bioactives, potentially useful for the development of functional foods and food supplements [1,2]. Starting from plant materials, numerous and different processes are used to obtain single bioactive substances or compounds belonging to the same chemical category. The recovery of high added-value components from food wastes can be carried out by traditional or innovative technologies. Among the latter, ultrasound-assisted extraction (UAE) can be considered a very successful and efficient extraction process for bioactive extraction [2].

Previous studies have reported the phytochemical composition of Lycium spp. berries and the availability of their bioactive compounds, including carotenoids, polyphenols, phytosterols, 
and phenolic acids [3-6]. Lycium leaves are interesting byproducts with health properties, due to the presence of polyphenols [7,8]. Nowadays, these bioactives are considered functional ingredients in the composition of different phytopharmaceuticals and dietary supplements due to numerous biological properties, among which are antioxidant, anti-inflammatory, and anti-hypertensive [9]. In addition to these activities, it has been reported that chlorogenic acid (CHA) shows an inhibitory effect on $\alpha$-amylase [10]. This enzyme, together with other digestive enzymes (e.g., $\alpha$-glucosaccharase, transglycosylase), is involved in the in vivo hydrolysis of starch into glucose, which, transported into blood, leads to postprandial hyperglycaemia. In particular, $\alpha$-amylase is the key digestive enzyme that acts on starch to release dextrin, disaccharides, or other low molecular-weight carbohydrates, which will be then broken down into glucose [11]. Since high blood glucose levels can be associated with diabetes or obesity, the inhibition of $\alpha$-amylase might be an effective way to reduce starch digestibility and thereby relieve postprandial glycaemia [11].

It has been reported in the literature that the extracts from leaves of various origin possessed inhibitory activity against $\alpha$-amylase [12-14]. Abdelli et al. [15] evaluated the inhibitory activity against $\alpha$-amylase of tannic acid, catechin, gallic acid, quercetin, and epicatechin by in silico approach, revealing that tannic acid can be used as alternative drug for the regulation of postprandial hyperglycaemia. Demir et al. [16] reported that genistein, tangeretin, pelargonidin, formononetin, and delphinidin showed antidiabetic properties. L. barbarum leaves also showed inhibition activity against various enzymes, among which cholinesterase, $\alpha$-amylase, and $\alpha$-glycosidase [8].

In this work, L. barbarum leaves were extracted with methanol by UAE and the phenolic acid profile was investigated by ultra-high-performance liquid chromatography quadrupole-time-of-flight tandem mass spectrometry (UHPLC-Q-TOF MS/MS) analysis. The identified phenolic acids were studied for $\alpha$-amylase inhibitory activity by in vitro approach. The objective of this research was also to assess a putative binding mode of active phenolic acids to human pancreatic $\alpha$-amylase. To the best of our knowledge, this is the first time that the evaluation of the inhibitory effect of individual phenolic acids, identified in the leaf extract, against porcine pancreatic $\alpha$-amylase is studied.

\section{Materials and Methods}

\subsection{Plant Sample}

Intact fresh leaves from L. barbarum, harvested in 2019 in Umbria (central Italy), were dried to constant weight in a ventilated oven (Binder, Series ED, Tuttlingen, Germany) at $40{ }^{\circ} \mathrm{C}$ for $72 \mathrm{~h}$. Then the dried leaves were ground to obtain a fine powder and stored in amber glass vial at room temperature in the dark, until extraction.

\subsection{Reagents}

Diammonium

2,2'-azino-bis(3-ethylbenzothiazoline-6-sulphonate)

(ABTS;

$\geq 98 \%$ ), 2,2-diphenyl-1-picrylhydrazyl (DPPH radical), Folin-Ciocalteu's phenol reagent, ( \pm )-6-hydroxy-2,5,7,8-tetramethylchromane-2-carboxylic acid (Trolox; 97\%), 2,4,6-tri(2-pyridyl)-s-triazine (TPTZ; $\geq 98 \%$ ), chlorogenic acid (CHA; 95\%), salicylic acid ( $\geq 99 \%)$, $p$-coumaric acid $(\geq 98 \%)$, sinapic acid $(\geq 98 \%)$, syringic acid $(\geq 95 \%)$, caffeic acid $(\geq 98 \%)$, vanillin $(99 \%)$, vanillic acid ( $\geq 97 \%)$, gallic acid (97.5-102.5\%), starch from potato, 3,5-dinitrosalicylic acid (DNSA; $\geq 98 \%$ ), sodium chloride ( $\geq 99.5 \%$ ), and $\alpha$-amylase from porcine pancreas (Type VI-B, $\geq 5$ units/mg solid) were acquired from Sigma-Aldrich (Milan, Italy). Acetonitrile, formic acid and ultrapure water from Carlo Erba Reagents (Milan, Italy) were UPLC-MS grade.

\subsection{Ultrasound-Assisted Extraction (UAE) of L. barbarum Leaves}

Dried L. barbarum leaves (330 mg) were extracted with pure methanol $(20 \mathrm{~mL})$ using an ultrasonic bath (mod. AU-65, ArgoLab, Carpi, Italy) with ultrasonic power of $180 \mathrm{~W}$. The extraction was carried 
out for $30 \mathrm{~min}$ at $45^{\circ} \mathrm{C}$, then the extract was filtered and collected in amber glass vials until the further analysis. The extraction was repeated three times.

\subsection{Determination of Total Phenol Content (TPC)}

The TPC was determined spectrophotometrically according to the method previously reported [17], based on redox reaction of phenols with Folin-Ciocalteu's reagent. Lambda 20 spectrophotometer (PerkinElmer, Inc.; Waltham, MA, USA) was used to measure the absorbance at $765 \mathrm{~nm}$. The TPC was expressed as mg of gallic acid equivalents (GAE) per gram of dry leaves (mg GAE/g).

\subsection{In Vitro Antioxidant Activities}

\subsubsection{Free Radical-Scavenging Activity Using DPPH Assay}

The measurement of the scavenging ability of phenolic extract towards the stable DPPH radical was performed by DPPH assay, using the procedure previously reported [18]. An aliquot $(3.9 \mathrm{~mL})$ of a $0.0634 \mathrm{mM}$ DPPH solution in methanol $(95 \%)$ was added to L. barbarum leaf extract $(100 \mu \mathrm{L})$ and vortexed for about 5-10 s. After $30 \mathrm{~min}$, the change in the absorbance was measured at $515 \mathrm{~nm}$ using the spectrophotometer reported in 2.4 Paragraph. The DPPH antiradical capacity was expressed as mg Trolox Equivalents (TE) per gram of dry leaves (mg TE/g).

\subsubsection{Free Radical-Scavenging Activity Using ABTS Assay}

ABTS assay was carried out following the procedure described by Urbani et al. [19]. The ABTS stock solution was prepared by mixing $7 \mathrm{mM}$ ABTS and $2.45 \mathrm{mM}$ of potassium persulphate as the oxidant agent. The sample extract $(200 \mu \mathrm{L})$ was added to ABTS ${ }^{+\cdot}$ solution $(1800 \mu \mathrm{L})$ and after $10 \mathrm{~min}$ the absorbance at $734 \mathrm{~nm}$ was measured using the spectrophotometer reported in 2.4 Paragraph. The ABTS antiradical capacity was expressed as $\mathrm{mg} \mathrm{TE} / \mathrm{g}$.

\subsubsection{Ferric Reducing Antioxidant Power (FRAP) Assay}

The reducing capacity of leaf extracts was determined using a modified method of the FRAP assay [20]. Freshly prepared FRAP reagent $(2.0 \mathrm{~mL})$ was mixed with L. barbarum extract $(100 \mu \mathrm{L})$ and distilled water $(900 \mu \mathrm{L})$, then the sample was left away from light at room temperature. After $30 \mathrm{~min}$ the absorbance at $593 \mathrm{~nm}$ was measured using the spectrophotometer reported in 2.4 Paragraph. Distilled water was used as blank. The FRAP value was expressed as mg TE/g.

\section{6. $\alpha$-Amylase Inhibition Activity Assay}

The inhibitory activity of $\alpha$-amylase was carried out according to the procedure reported by Wu et al. [21]. L. barbarum extract solutions were mixed with $\alpha$-amylase and maintained at $30^{\circ} \mathrm{C}$ for $10 \mathrm{~min}$. Then, soluble starch solution was added as substrate and the hydrolysis was carried out at $30^{\circ} \mathrm{C}$. After $3 \mathrm{~min}$, DNSA reagent was added, and the mixture was placed in a boiling water bath at $80^{\circ} \mathrm{C}$ for $15 \mathrm{~min}$. Afterwards, the solutions were diluted with water, and then the absorbance at $540 \mathrm{~nm}$ (Abs extract) was measured using a Lambda 20 spectrophotometer. For each concentration of the L. barbarum extract, a blank incubation was prepared by replacing the enzyme solution with distilled water, to correct for absorbance due the L. barbarum extract (Abs blank extract). A control incubation, representing $100 \%$ enzyme activity, was carried out by replacing L. barbarum extract with the vehicle, and Abs control was measured. The same test was also carried out without the enzyme and Abs blank control was registered. The $\alpha$-amylase inhibitory activity was calculated as percentage inhibition using the following formula:

$$
\% \text { inhibition }=\frac{(\Delta \text { Abs control }-\Delta \text { Abs extract })}{\Delta \text { Abs control }} \times 100
$$


where

$$
\begin{gathered}
\Delta \text { Abs control }=\text { Abs control }- \text { Abs blank control } \\
\Delta \text { Abs extract }=\text { Abs extract }- \text { Abs blank extract }
\end{gathered}
$$

The concentration of the extract able to inhibit the $\alpha$-amylase activity by $50 \%\left(\mathrm{IC}_{50}\right)$ was calculated by regression analysis. Single phenolic acids were also tested for $\alpha$-amylase inhibitory activity and their $\mathrm{IC}_{50}$ values were determined as above described. Acarbose was also analyzed as a known $\alpha$-amylase inhibitor.

\subsection{Analysis of Phenolic Acids by Q-TOF-LC/MS}

The ultra-high-performance Accurate-Mass Q-TOF-LC/MS analysis was performed using an Agilent Technologies (Santa Clara, CA, USA) 1200 Infinity Series LC coupled with an Agilent Technologies 6540 UHD Accurate-Mass Q-TOF-LC/MS. This device was equipped with an electrospray ionization Agilent Technologies Dual Jet Stream ion source (Dual AJS ESI). Chromatographic separation was carried out with an Agilent Infinity lab Poroshell 120 EC-C18 $(3 \times 100 \mathrm{~mm}, 2.7 \mu \mathrm{m})$ column. The injection volume was $10 \mu \mathrm{L}$. The mobile phase consisted of $0.1 \%$ formic acid in water milli-Q (solvent $\mathrm{A}$ ) and acetonitrile (solvent $\mathrm{B}$ ), at a flow rate of $0.5 \mathrm{~mL} / \mathrm{min}$, with the following gradient: 0-10 $\mathrm{min}, 5 \% \mathrm{~B} ; 10-13 \mathrm{~min}, 95 \% \mathrm{~B} ; 13-15 \mathrm{~min}, 95 \% \mathrm{~B}$. The Q-TOF-MS conditions were the following: drying gas flow $\left(\mathrm{N}_{2}\right), 12.0 \mathrm{~L} / \mathrm{min}$; nebulizer pressure, $45 \mathrm{psi}$; gas drying temperature, $370{ }^{\circ} \mathrm{C}$; capillary voltage, $3500 \mathrm{~V}$; fragmentor voltage, $110 \mathrm{~V}$; skimmer voltage $65 \mathrm{~V}$ and octopole RF peak, $750 \mathrm{~V}$. Dual AJS ESI interface was used in negative ionization mode and negative ions were acquired in the range of $100-1100 \mathrm{~m} / \mathrm{z}$ for MS scans, and 50-600 m/z for auto MS/MS scans, at a scan rate of $5 \mathrm{scans} / \mathrm{s}$ for MS and 3 scans/s for MS/MS, respectively. Automatic acquisition mode MS/MS were carried out using the following collision energy values: $\mathrm{m} / \mathrm{z} 20 \mathrm{eV}, \mathrm{m} / \mathrm{z} 30 \mathrm{eV}$, and $40 \mathrm{eV}$. Internal mass correction was enabled using two reference masses at 121.0509 and $922.0098 \mathrm{~m} / \mathrm{z}$. Instrument control and data acquisition were performed using Agilent MassHunter Workstation software B.08.00. All the MS and MS/MS data of the validation standards were integrated by MassHunter Quantitative Analysis B.10.0 (Agilent Technologies).

\subsection{Molecular Docking}

The crystal structure of human pancreatic $\alpha$-amylase (PDB ID: 5KEZ) was downloaded from the Research Collaboratory for Structural Bioinformatics Protein Data Bank (RCSB PDB; https://www. rcsb.org/) [22], removing the peptide inhibitor from the active site. The optimization procedure was performed using the Protein Preparation Wizard tool implemented in Maestro (Maestro, Version 12.1, Schrödinger, LLC, New York, NY, USA, 2019). In particular, this procedure included the refinement of the hydrogen bond network that was performed using the default setting. The OPLS3e force field was used for the energy minimization of the protein structure, restraining atomic coordinates of heavy atoms. Atomic coordinates of chemical structures were retrieved from the PubChem database (https://pubchem.ncbi.nlm.nih.gov/) [23]. LigPrep (v.8.4) was then used to add hydrogens, and Epik (Epik, Version 2.5, Schrödinger, LLC, New York, NY, USA, 2013) to generate tautomeric and protonation states at $\mathrm{pH} 7.0 \pm 2.0$. Next, energy minimization of chemical structures was carried out with the OPLS3e force field until reaching an energy gradient convergence criteria of $0.05 \mathrm{~kJ} / \AA ̊ \AA$ mol. Docking simulations were performed using Glide (v.8.4) [24,25]. Specifically, a grid box was defined with its center located on the center of mass of binding site residues in the reference structure 5KEZ. These residues included Ala128, Pro130, Tyr131, Ser132, Tyr151, Asp197, Lys200, His201, Glu233, Ile235, Asp300, and His305. The inner grid box was sized $10 \times 10 \times 10 \AA$. Docking studies were carried out using the standard precision (SP) method and the Gscore scoring function. The top ten scored binding poses were stored for each molecule. The binding mode for each compound was selected in terms of the best docked pose showing the highest number of ligand/target interactions (electrostatic interactions, hydrogen bonds, $\pi$-stacking/cation interactions, hydrophobic contacts) and lowest Gscore 
( $\mathrm{kcal} / \mathrm{mol})$. Experimental or calculated acidic constants $(\mathrm{pKa})$ of phenolic acids were retrieved from DrugBank [23,26].

\subsection{Statistical Analysis}

Each analytical procedure was carried out in triplicate and the results, reported on dry leaves, were expressed as mean \pm standard deviation (SD). For data analysis Microsoft Excel 2016 (Microsoft Corporation, Redmond, WA, USA) was used.

\section{Results and Discussion}

\subsection{Characterization of L. barbarum Leaf Extract and $\alpha$-Amylase Inhibition of Constituent Phenolic Acids}

In this study, L. barbarum leaf extract was obtained by nonconventional UAE using methanol as solvent. This extraction process was chosen on the basis of the results obtained in a recent paper [7], which showed that UAE is a very successful and efficient technique for extracting phenols from L. barbarum leaves, also in comparison with microwave-assisted extraction. UAE methanolic extraction yield $(20.39 \% \pm 1.08 \mathrm{SD})$ was calculated taking into consideration the weight of the extract residue obtained after solvent removal and the initial weight of leaf powder [7]. The obtained residue was first characterized by evaluating the phenol content and antioxidant activity, then the phenolic acid profile was determined by Q-TOF-LC/MS analysis. The total phenolic content, determined according to the Folin-Ciocalteu method, was $7.75 \mathrm{mg} \mathrm{GAE} / \mathrm{g} \pm 0.43 \mathrm{SD}$; similar findings have been previously reported in other studies regarding Italian and Romanian L. barbarum leaves [7,8]. Mocan et al. reported values of $11.14 \mathrm{mg} \mathrm{GAE} / \mathrm{g} \mathrm{dw}$ (dry weight) and $11.98 \mathrm{mg} \mathrm{GAE} / \mathrm{g} \mathrm{dw}$ for Bigligeberry and Erma cultivars, respectively, while for wild-growing $L$. barbarum leaves a lower amount (2.49 $\mathrm{mg} \mathrm{GAE} / \mathrm{g} \mathrm{dw}$ ) was reported [8].

The evaluation of the antioxidant activity, based on different complementary assays, is a routine analysis commonly carried out to characterize vegetable extracts. The antioxidant capacity of L. barbarum leaf extract was measured using three spectrophotometric methods, DPPH and ABTS assays determining antiradical activity, and FRAP assay determining reducing power; the results are shown in Figure 1.

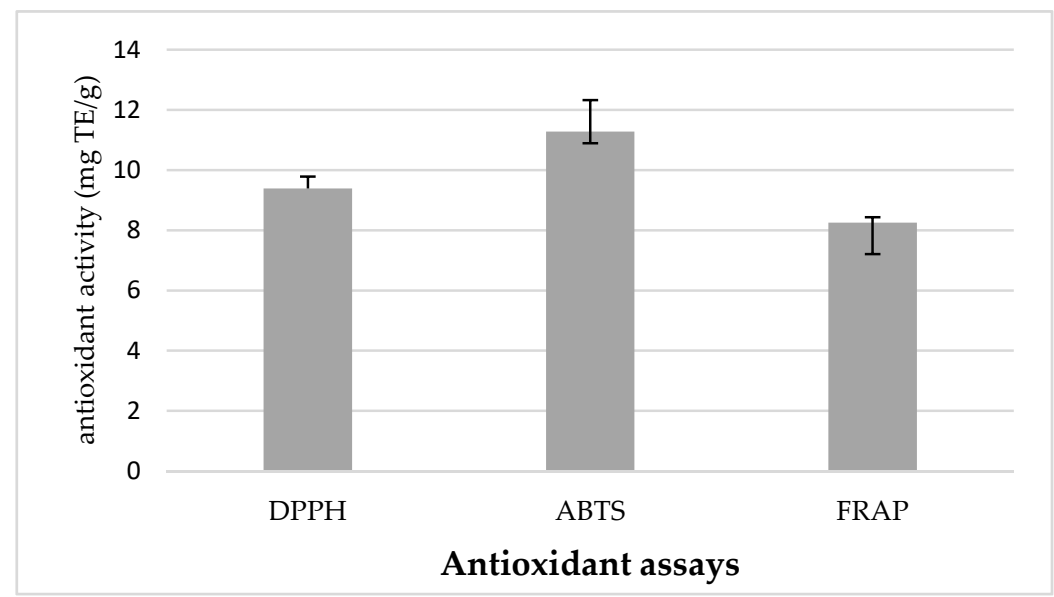

Figure 1. Values of in vitro antioxidant activities of $L$. barbarum leaf extracts, evaluated by DPPH, ABTS, and FRAP assays. The error bars represent the standard deviation $(\mathrm{n}=3$ ). DPPH, 2,2-diphenyl-1-picrylhydrazyl; ABTS, diammonium 2,2'-azino-bis(3-ethylbenzothiazoline-6-sulphonate), FRAP, ferric reducing antioxidant power.

The results obtained for the DPPH and ABTS radical-scavenging assays were $9.39 \mathrm{mg} \mathrm{TE} / \mathrm{g}$ and $11.28 \mathrm{mg} \mathrm{TE} / \mathrm{g}$, respectively, while $8.25 \mathrm{mg}$ TE/g was obtained by FRAP assay. The lower value obtained for DPPH assay in respect to ABTS assay can be attributed to the steric hindrance effects 
and the chemical characteristics of the phenolic compounds. Mocan et al. [8] reported different antioxidant values obtained by ABTS assay for leaves of two cultivars of Romanian L. barbarum and from wild-growing plants. Other authors studied the antioxidant activity of another plant source of chlorogenic and neochlorogenic acids, plum fruits of three different species, and found lower ABTS values [27]. In another paper, Mocan et al. [28] studied the antioxidant capacity of L. barbarum and L. chinense leaves from Romania using DPPH, ABTS, and hemoglobin ascorbate peroxidase activity inhibition assays and found higher values for L. chinense than L. barbarum leaves. ABTS values similar to those obtained in this work were obtained for other vegetable waste, such as olive leaves harvested in different season from different Olea europaea cultivar [1]. However, it is important to highlight that it is not always possible to make comparisons with antioxidant data reported in the literature, in particular for DPPH and FRAP data, since the results of the same assay can be expressed with different measure unit. In this regard, it is known that antioxidant activity of leaf extracts is strongly dependent on the harvesting season, cultivar, and extraction conditions [1,20]. In this study, a Q-TOF-LC/MS analysis was carried out to investigate the qualitative and quantitative profile of phenolic acids in the UAE methanolic extract of L. barbarum leaves, considering that the main objective of this paper was the in vitro and in silico study of the inhibitory activity of this category of phenolic compounds against porcine pancreatic $\alpha$-amylase. Figure 2 shows the chemical structures of the main phenolic acids identified in the methanolic extract of L. barbarum leaves, while Table 1 shows their content.<smiles>COc1cc(C(=O)O)cc(OC)c1O</smiles>

1<smiles>COc1cc(C(=O)O)ccc1O</smiles>

5<smiles>O=C(/C=C/c1ccc(O)c(O)c1)O[C@H]1C[C@@](O)(C(=O)O)C[C@H](O)[C@H]1O</smiles>

2<smiles>O=C(O)/C=C/c1ccc(O)cc1</smiles>

6<smiles>O=C(O)c1ccccc1O</smiles>

3<smiles>COc1cc(/C=C/C(=O)O)cc(OC)c1O</smiles>

7<smiles>O=C(O)/C=C/c1ccc(O)c(O)c1</smiles>

4<smiles>COc1cc(C=O)ccc1O</smiles>

8

Figure 2. Chemical structures of the main phenolic acids identified in the L. barbarum leaf extract. 1: syringic acid; 2: chlorogenic acid; 3: salicylic acid; 4 : caffeic acid; 5: vanillic acid; $6: p$-coumaric acid; 7: sinapic acid; 8: vanillin.

Table 1. Phenolic acid content $(\mu \mathrm{g} / \mathrm{g} \pm \mathrm{SD})$ of L. barbarum leaf extract.

\begin{tabular}{|c|c|c|c|c|c|c|c|}
\hline n. & Compounds & $\begin{array}{c}\text { Concentration } \\
(\mu \mathrm{g} / \mathrm{g})\end{array}$ & Rt (min) & $\begin{array}{l}\text { Mass Calculated } \\
\left(\mathrm{m} / \mathrm{z}, \mathbf{M}-\mathrm{H}^{-}\right)\end{array}$ & $\begin{array}{l}\text { MS Fragments } \\
\left(\mathrm{m} / \mathrm{z}, \mathrm{M}-\mathrm{H}^{-}\right)\end{array}$ & $\begin{array}{l}\text { Error } \\
(p p m)\end{array}$ & Score \\
\hline 1 & Syringic acid & $0.76 \pm 0.000$ & 4.39 & 197.0458 & $123.0083 / 147.8891 / 95.0138$ & -1.22 & 98.26 \\
\hline 2 & Chlorogenic acid & $358.34 \pm 0.004$ & 4.69 & 354.0955 & $191.0543 / 127.0397 / 85.0301$ & -1.22 & 98.72 \\
\hline 3 & Salicylic acid & $239.02 \pm 0.005$ & 5.13 & 137.0247 & $93.0351 / 65.0405$ & -1.23 & 99.41 \\
\hline 4 & Caffeic acid & $0.07 \pm 0.000$ & 5.67 & 180.0432 & $135.0447 / 107.0506 / 89.0404$ & -1.10 & 97.22 \\
\hline 5 & Vanillic acid & $9.46 \pm 0.002$ & 6.39 & 167.0350 & $108.0218 / 123.0458 / 91.0196$ & -1.34 & 97.11 \\
\hline 6 & $p$-Coumaric acid & $0.84 \pm 0.000$ & 6.58 & 223.0619 & $164,0483 / 119.0497 / 93.0349$ & -1.50 & 97.23 \\
\hline 7 & Sinapic acid & $2.36 \pm 0.000$ & 6.69 & 283.0833 & $224.0696 / 149.0232 / 93.0350$ & -1.71 & 99.34 \\
\hline 8 & Vanillin & $8.62 \pm 0.003$ & 4.47 & 197.0457 & $146.7437 / 136.016 / 76.9614$ & -1.67 & 96.44 \\
\hline
\end{tabular}

Data are reported as mean $\pm S D$ of three independent measurements $(n=3)$ and are expressed on dry leaves.

CHA was the main phenol compound $(358.34 \mu \mathrm{g} / \mathrm{g})$, followed by salicylic acid $(239.02 \mu \mathrm{g} / \mathrm{g})$. These two molecules are also reported in two systematic Lycium reviews [29,30]. CHA was previously described as dominant in the leaves of wild and cultivated L. barbarum [8,28,31,32], but also in L. chinense leaves $[28,32]$. Caffeic, chlorogenic, $p$-coumaric, and vanillic acids were also certainly identified by 
Inbaraj et al. [31]. It is widely reported in the literature that the phenolic profile of leaves may strongly change according to the type of plant, seasonal conditions, and extraction method $[1,7,20]$.

In order to evaluate the capacity of the L. barbarum extract to inhibit the $\alpha$-amylase, and, therefore, the potential hypoglycemic effect, an in vitro assay based on the spectrophotometric evaluation of the hydrolytic activity of porcine pancreatic $\alpha$-amylase was carried out. The linear regression equations, obtained plotting $\alpha$-amylase \% inhibition versus concentration of the standard phenolic acids and UAE methanolic extract are reported in Table 2. The $\mathrm{R}^{2}$ values and the $\mathrm{IC}_{50}$ values are shown in the same Table. The $\mathrm{IC}_{50}$ value for Acarbose was $0.1 \mathrm{mg} / \mathrm{mL}$, while Min and Han [33] reported a value of $0.45 \mathrm{mg} / \mathrm{mL}$. The results revealed that the percentage of $\alpha$-amylase inhibition increased for chemical standards in a dose-dependent manner, with a linear trend, as also reported in other papers [10,34], with good $\mathrm{R}^{2}$ values (from 0.9987 of CHA to 0.9999 of sinapic acid).

Table 2. Linear regression equations, $\mathrm{R}^{2}$ values and $\mathrm{IC}_{50}$ values of phenolic acids and $L$. barbarum leaf extract for $\alpha$-amylase inhibition activity.

\begin{tabular}{lccccc}
\hline \multirow{2}{*}{$\mathbf{n}$} & Compounds & \multicolumn{2}{c}{ Regression Equation } & \multirow{2}{*}{$\mathbf{R}^{\mathbf{2}}$} & \multirow{2}{\text{IC}_{\mathbf{50}}}{$\mathbf{\text { mg/mL }}$} \\
\cline { 3 - 4 } & & Slope & Intercept & & \\
\hline $\mathbf{1}$ & Syringic acid & 46.400 & -228.280 & 0.9925 & 6.0 \\
$\mathbf{2}$ & Chlorogenic acid & 178.560 & -37.986 & 0.9987 & 0.5 \\
$\mathbf{3}$ & Salicylic acid & 384.000 & -633.930 & 0.9930 & 1.8 \\
$\mathbf{4}$ & Caffeic acid & 15.923 & -5.776 & 0.9995 & 3.5 \\
$\mathbf{5}$ & Vanillic acid & 12.512 & -27.403 & 0.9996 & 6.2 \\
$\mathbf{6}$ & p-Coumaric acid & 10.627 & -9.487 & 0.9989 & 5.6 \\
$\mathbf{7}$ & Sinapic acid & 8.863 & -23.288 & 0.9999 & 8.3 \\
$\mathbf{8}$ & Vanillin & 4.808 & -1.849 & 0.9990 & 10.8 \\
& Acarbose & 0.553 & -18.057 & 0.9980 & 0.1 \\
& L. barbarum leaf extract & 2.185 & -5.520 & 0.9977 & 25.4 \\
\hline
\end{tabular}

Higher $\alpha$-amylase inhibitory activity was found for CHA, salicylic, and caffeic acids than the other constituents. On the other hand, the inhibitory activity of the L. barbarum methanolic extract was lower than the individual phenolic acids, probably due to the complexity of the chemical composition of vegetable matrices, as leaves. However, comparable results were reported by other authors [35], which found an $\mathrm{IC}_{50}$ value of $23.7 \mathrm{mg} / \mathrm{mL}$ for ethanolic extract of dried Garcinia schomburgkiana leaves. Antidiabetic properties of phenolic compounds were reported in other papers, regarding phenolic compounds from leaves [8], fruits [36], and plants [37]. It has been reported that natural compounds, such as phenolics, may bind by hydrogen bonding the amino acid residues in the active sites of digestive enzyme. In this way, the hydrolysis reaction of digestive enzymes on carbohydrates may be inhibited and consequently slowed down their absorption [21]. Only few data on enzyme inhibition potential of Lycium leaves are reported, as for example Mocan et al. reported similar results for amylase inhibitory activity (0.24-0.26 mmol Acarbose equivalents/g extract) for L. barbarum considered samples [8].

Abdelli et al. [15] reported that tannic acid showed a stronger $\alpha$-amylase inhibitory capacity $\left(\mathrm{IC}_{50}=3.46 \mu \mathrm{g} / \mathrm{mL}\right)$ in comparison with Acarbose $\left(\mathrm{IC}_{50}=10.41 \mu \mathrm{g} / \mathrm{mL}\right)$. Demir et al. [16] found that phenolic compounds exhibit potential inhibitor properties for $\alpha$-amylase, $\alpha$-glycosidase and aldose reductase. For $\alpha$-amylase assay, the authors reported $\mathrm{IC}_{50}$ values from $601.56 \mathrm{nM}$ of delphinidin chloride to $2067.78 \mathrm{nM}$ of pelargonidin, while 10,000 $\mathrm{nM}$ for Acarbose was reported.

The investigation of the amylase inhibitory activity of the individual phenolic acids showed that some molecules (chlorogenic acid, CHA, 2; caffeic acid, 4; salicylic acid, 3) had inhibitory activity against the key carbohydrate digestive enzyme, while other molecules (syringic acid, $1 ; p$-coumaric acid, 6; vanillic acid, 5; sinapic acid, 7; vanillin, 8) showed lower inhibition potency. These results confirmed that $\mathrm{CHA}(2)$ has high inhibitory activity against $\alpha$-amylase. It has been reported that this should be due to its ability to form quinones, rather than semiquinones [34]. Sinapic and caffeic acids are less active than CHA (2), as also reported by Funke and Melzig [34]. Notably, in this work 
the inhibition mechanism of the main phenolic compounds toward this key digestive enzyme was investigated by molecular docking analysis, in order to provide a better understanding of how the considered phenolic acids inhibit $\alpha$-amylase activity.

\subsection{Docking Studies}

In order to infer a putative binding mode of active phenolic acids (1-8) to the enzyme, docking studies were carried out using the human pancreatic $\alpha$-amylase that shares $90 \%$ of sequence similarity with the porcine isoform (Figure 3).

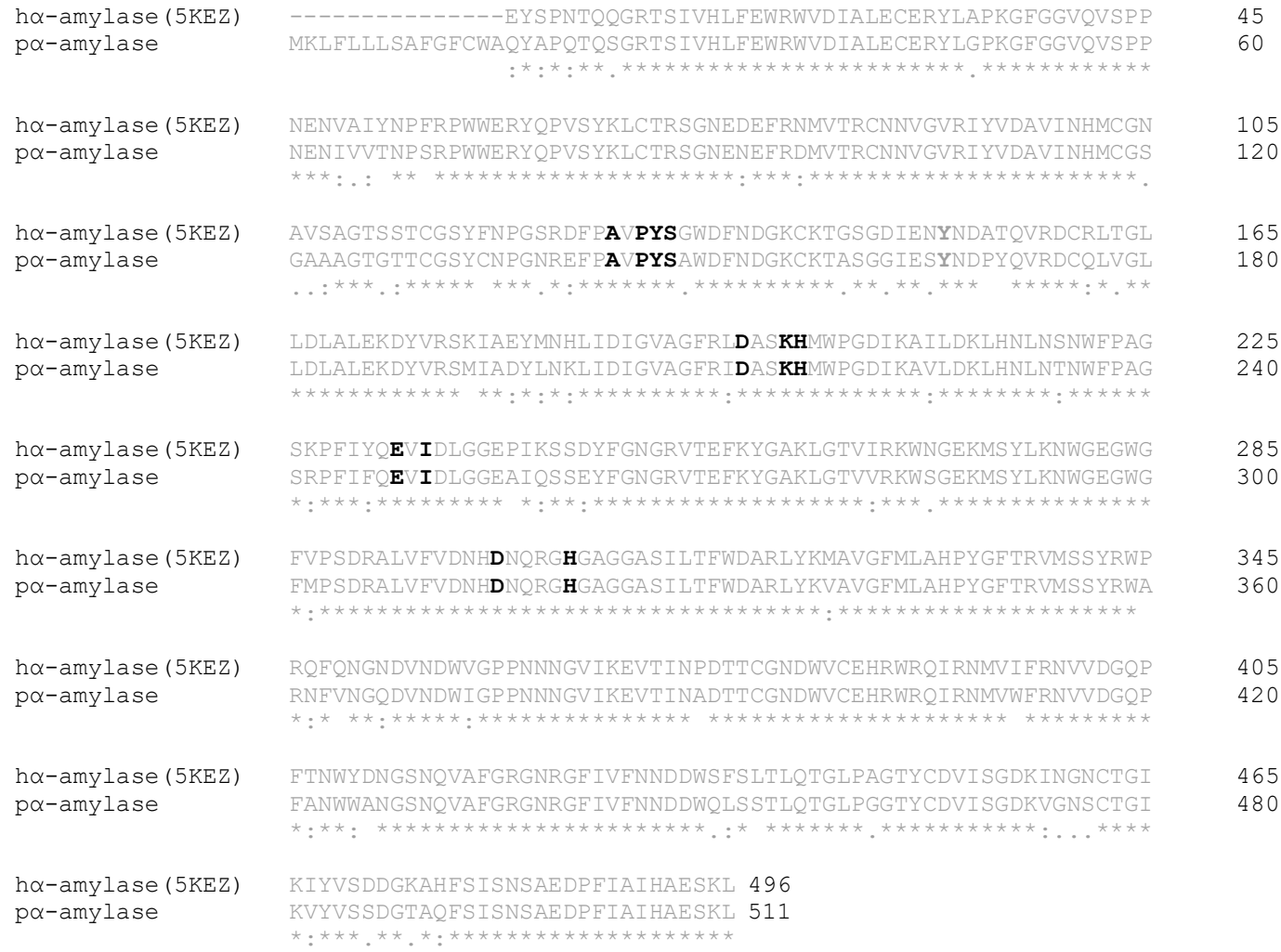

Figure 3. Sequence alignment between human pancreatic $\alpha$-amylase (h $\alpha$-amylase; 5KEZ) and porcine pancreatic $\alpha$-amylase (p $\alpha$-amylase) as generated with Clustal Omega (www.ebi.ac.uk/Tools/msa/ clustalo/). Binding site residues selected for docking studies are bold typed. Symbols at the bottom indicate identity $\left(^{*}\right)$, high (:) or moderate (.) similarity.

In particular, the crystal structure of the enzyme in complex with a peptide inhibitor (pdb code: $5 \mathrm{KEZ})$ as reference structure was used [38]. Firstly, $\mathrm{CHA}(\mathbf{2}$, calc pKa $=3.3)$ was docked into the enzyme and the resulting binding mode is shown in Figure 4. CHA forms hydrogen bonds between the three hydroxyl groups of the cyclohexane ring and the side chains of Asp197, Glu233, and Asp300. An additional hydrogen bond is observed between the para hydroxyl group of the caffeic acid moiety and the side chain of Glu240, whereas the phenyl ring engages Lys200 with a $\pi$-cation interaction (Figure 4). 


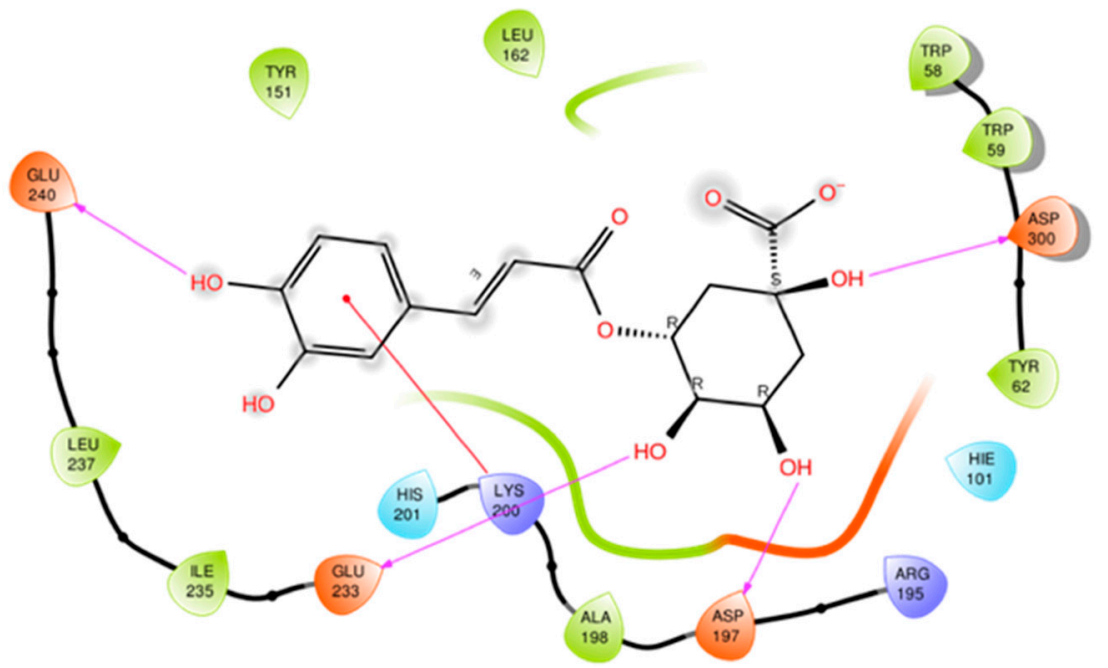

Figure 4. Binding mode of chlorogenic acid (CHA) (1) to human pancreatic $\alpha$-amylase as resulting from the docking study (Gscore $=-4.10 \mathrm{kcal} / \mathrm{mol}$ ). Hydrogen bonds are shown with magenta arrows. $\pi$-Cation interaction is shown with red line. Polar and hydrophobic contacts between ligand and enzyme residues are displayed with red and green faded tick lines, respectively.

Caffeic acid $(4, \exp \mathrm{pKa}=4.6)$ is a structural fragment of CHA. The docking study of this compound into the crystal structure of human pancreatic $\alpha$-amylase yields a binding mode wherein the carboxylic group engages the side chain of Lys200 with a salt bridge interaction, while making a hydrogen bond with the backbone amide group of Ile235 (Figure 5A). The shift of the molecule within the active site of the enzyme with respect to the ester fragment of $\mathrm{CHA}$ is driven by the electrostatic interaction of the free carboxylic group with Lys200.

A

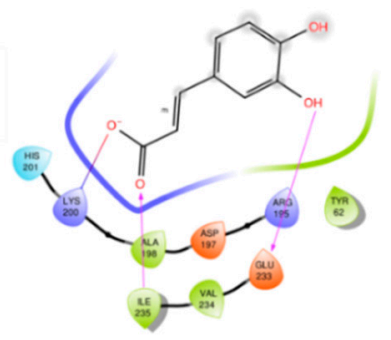

B

10.1

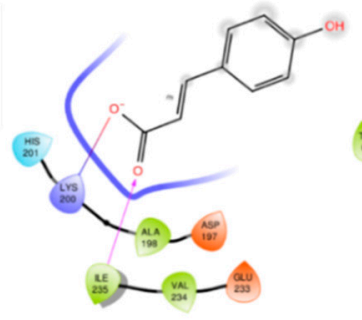

C

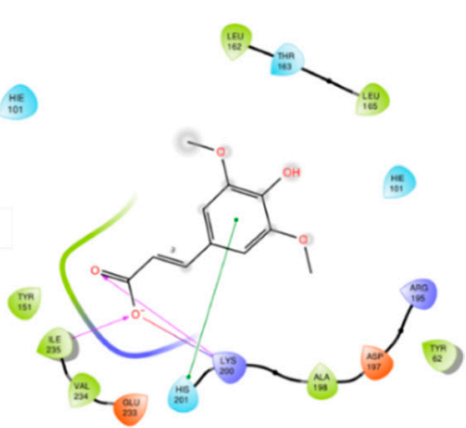

Figure 5. Binding mode of caffeic acid (A; 4 Gscore $=-4.02 \mathrm{kcal} / \mathrm{mol}$ ), $p$-coumaric acid $(\mathbf{B} ; 6$ Gscore $=-3.56 \mathrm{kcal} / \mathrm{mol})$, and sinapic acid $(\mathbf{C} ; 7$ Gscore $=-3.89 \mathrm{kcal} / \mathrm{mol})$, to human pancreatic $\alpha$-amylase. Salt bridge interaction is depicted with a continuous blue/red faded line. Hydrogen bonds are shown with magenta arrows. $\pi$-Stacking interaction is plotted with a green capped line. Polar and hydrophobic contacts between ligand and enzyme residues are displayed with blue and green faded tick lines, respectively.

Differently from CHA, such a shift places the meta hydroxyl moiety in a complementary position for the formation of a hydrogen bond with Glu233. $p$-Coumaric acid $(6$, calc $p K a=3.8)$ lacks the meta hydroxyl moiety while keeping the para hydroxyl group of caffeic acid. As a result of the docking study, this compound adopts a binding mode akin to caffeic acid, keeping the interactions with Lys200 and Ile235 while losing the hydrogen bond with Glu233 (Figure 5B). This binding mode is also found in the docking study of sinapic acid $(7$, calc $\mathrm{pKa}=3.4)$ to human pancreatic $\alpha$-amylase, wherein a 
further $\pi$-stacking interaction is also observed between the substituted aromatic moiety and His201 (Figure 5C).

Since a fraction of vanillin $(8, \exp \mathrm{pKa}=7.4)$ exists in the anionic form at the experimental $\mathrm{pH}$ of the inhibition assay $(\mathrm{pH}=6.9)$, this compound was docked using both the neutral form and negatively charged form. These forms adopt a binding mode that is markedly affected by the electrostatic interaction with Lys200 (Figure 6). In the anionic form, the hydroxylate group of vanillin is placed nearby Lys200, forming a salt bridge interaction with this residue and a hydrogen bond with the backbone amide group of Ile235. A further hydrogen bond is observed between the methoxy group and the side chain of Lys200, whereas a $\pi$-stacking interaction is found between the imidazole ring of His201 and the aromatic moiety of vanillin. No specific interactions are observed for the aldehyde group of the anionic form of vanillin. In the neutral form, only the $\pi$-stacking interaction with His 201 is kept, while the aldehyde group engages the backbone carbonyl group of Ile235 with a hydrogen bond.

A

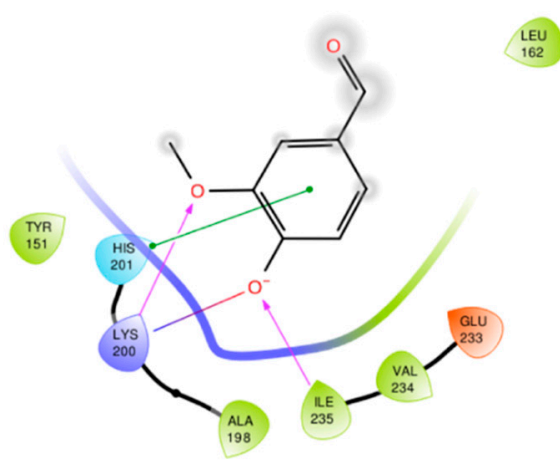

B

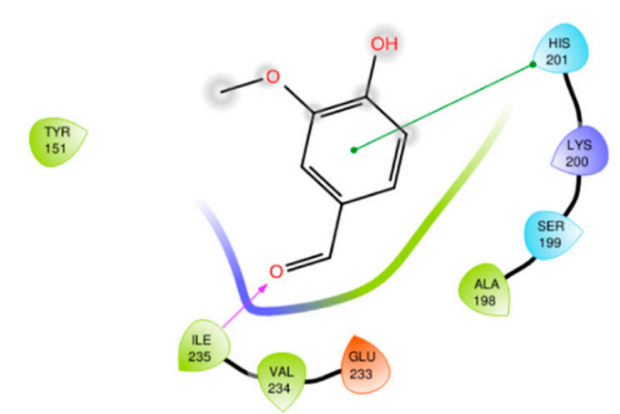

Figure 6. Binding mode of vanillin (8) to human pancreatic $\alpha$-amylase according to its anionic $(\mathbf{A}$; Gscore $=-3.70 \mathrm{kcal} / \mathrm{mol}$ ) and neutral (B; Gscore $=-5.59 \mathrm{kcal} / \mathrm{mol})$ form. Salt bridge interaction is depicted with a continuous blue/red faded line. Hydrogen bonds are shown with magenta arrows. $\pi$-Stacking interaction is plotted with a green capped line. Polar and hydrophobic contacts between ligand and enzyme residues are displayed with blue and green faded tick lines, respectively.

Akin to the anionic form of vanillin, vanillic acid $(5, \exp p K a=4.5)$ adopts a binding mode featured by a conserved salt bridge interaction with Lys200 and a $\pi$-stacking interaction with His201 (Figure 7A). A further hydrogen bond is established between the para hydroxyl group of this compound and Glu233.

Two additional analogues of vanillic acid are salicylic acid $(3, \exp p K a=2.97)$ and syringic acid $(\mathbf{1}$, calc pKa $=3.9)$. Docking studies of these compounds reveal conserved binding modes in which both compounds engage Lys200 and His201 with salt bridge and $\pi$-stacking interactions, respectively (Figure 7B,C). A further hydrogen bond interaction is observed between the backbone amide group of Ile235 and carboxyl group of salicylic acid and syringic acid. At odds with vanillic acid, no hydrogen bond is made by the para hydroxyl group of syringic acid, which is due to the steric shield provided by the two methoxy groups in meta positions of the benzene ring. Overall, results of docking studies allow drawing relationships among chemical structure, pKa property, binding mode and inhibition activity of tested compounds. Specifically, the conserved salt bridge or $\pi$-cation interaction between the anionic carboxylate or aromatic ring and Lys200 is found important for the inhibition activity. Indeed, vanillin $\left(8, \mathrm{IC}_{50}=10.8 \mathrm{mg} / \mathrm{mL}\right)$ shows a significant drop of activity being in part present as neutral form at the experimental $\mathrm{pH}$ for its poor acidic constant $(\exp \mathrm{pKa}=7.4)$. The higher inhibition activity of CHA $\left(2, \mathrm{IC}_{50}=0.5 \mathrm{mg} / \mathrm{mL}\right)$ with respect to caffeic acid $\left(4, \mathrm{IC}_{50}=3.5 \mathrm{mg} / \mathrm{mL}\right)$ suggests that the binding interaction of the quinic acid moiety of CHA is important for the inhibition potency, making the hydrogen bond interactions between its three hydroxyl groups and the acidic residues Asp197, 
Glu233, and Asp300. Likewise, the hydrogen bond interaction of the meta hydroxyl group of caffeic acid (4) with Glu233 favors the inhibition activity against pancreatic $\alpha$-amylase. Indeed, removal or methylation of this group determines a decrease of the inhibition activity in $p$-coumaric acid (6, $\left.\mathrm{IC}_{50}=5.6 \mathrm{mg} / \mathrm{mL}\right)$ and sinapic acid $\left(7, \mathrm{IC}_{50}=8.3 \mathrm{mg} / \mathrm{mL}\right)$, respectively. This trend is also observed in the shorter homologues of caffeic acid (4), namely vanillic acid $\left(5, \mathrm{IC}_{50}=6.2 \mathrm{mg} / \mathrm{mL}\right)$ and syringic acid $\left(\mathbf{1}, \mathrm{IC}_{50}=6.0 \mathrm{mg} / \mathrm{mL}\right)$. Conversely, salicylic acid $\left(3, \mathrm{IC}_{50}=1.8 \mathrm{mg} / \mathrm{mL}\right)$ keeps a similar inhibition activity to caffeic acid, albeit its ortho hydroxyl group is not involved in any hydrogen bond interaction with the enzyme binding site. Hence, the better inhibition activity of salicylic acid $\left(3, \mathrm{IC}_{50}=1.8 \mathrm{mg} / \mathrm{mL}\right)$ than vanillic acid $\left(5, \mathrm{IC}_{50}=6.2 \mathrm{mg} / \mathrm{mL}\right)$ and syringic acid $\left(\mathbf{1}, \mathrm{IC}_{50}=6.0 \mathrm{mg} / \mathrm{mL}\right)$ may likely be explained by the lowest acidic constant of this compound $(3, \exp \mathrm{pKa}=2.97)$ that favors a stronger electrostatic salt bridge interaction with Lys200.

A

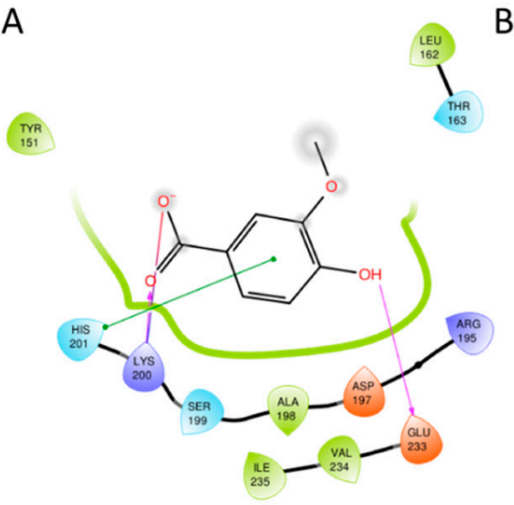

B

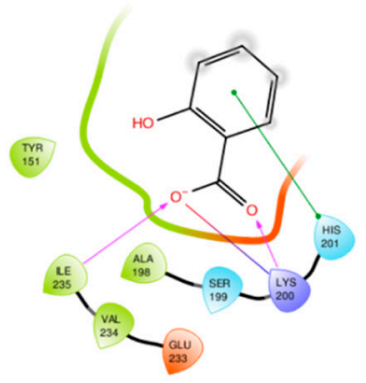

C

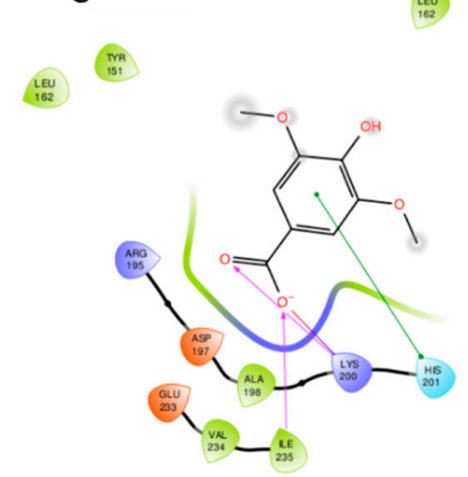

Figure 7. Binding mode of vanillic acid (A; 5 Gscore $=-4.65 \mathrm{kcal} / \mathrm{mol}$ ), salicylic acid (B; 3 Gscore $=-4.84 \mathrm{kcal} / \mathrm{mol}$ ) and syringic acid (C; 1 Gscore $=-4.32 \mathrm{kcal} / \mathrm{mol})$, to human pancreatic $\alpha$-amylase. Salt bridge interaction is depicted with a continuous blue/red faded line. Hydrogen bonds are shown with magenta arrows. Polar and hydrophobic contacts between ligand and enzyme residues are displayed with blue and green faded tick lines, respectively.

\section{Conclusions}

In the present work, for the first time several phenolic acids, identified in L. barbarum leaf extract, have been studied for their inhibitory activity against porcine pancreatic $\alpha$-amylase by in vitro and in silico approaches. The results obtained by in vitro assay indicated that phenolic acids had interesting $\alpha$-amylase inhibitory activity and showed that chlorogenic acid as the most active compound, followed by caffeic and salicylic acids with one-fold lower inhibition activity. The high sequence similarity between porcine and human isoforms of the enzyme (90\%) suggests that such results may apply in both species. Results of docking studies identifies the interaction with Lys200 as important for the inhibition activity of tested extracts from L. barbarum leaves. Although further studies are needed to investigate the nutraceutical potential of these natural extracts for the management of hyperglycemia related disorders, findings of this study support the $\alpha$-amylase inhibitory properties of phenolic acids, commonly represented in plant extracts.

Author Contributions: Conceptualization, A.M., F.B., L.C., J.M.; methodology, A.R., L.P., L.C., F.I., C.T., C.J.; software, A.M., L.C.; formal analysis, A.R., L.P., F.I., C.T., C.J.; resources, F.B., L.C., J.M.; data curation, A.R., L.P., F.I., C.T., C.J.; writing—original draft preparation, A.R., L.P., F.B., L.C., C.T.; writing—review and editing, A.M., F.B., L.C., J.M.; supervision, A.M., F.B., L.C.; project administration A.M., L.C., J.M. All authors have read and agreed to the published version of the manuscript.

Funding: This work was supported by funding from the University of Perugia: Fondo d'Ateneo per la Ricerca di Base 2018, Project "Caratterizzazione di composti bioattivi estratti da matrici vegetali".

Acknowledgments: The authors thank Giuseppa Verducci for her support in the chemical analysis. 
Conflicts of Interest: The authors declare no conflict of interest.

\section{References}

1. Blasi, F.; Urbani, E.; Simonetti, M.S.; Chiesi, C.; Cossignani, L. Seasonal variations in antioxidant compounds of Olea europaea leaves collected from different Italian cultivars. J. Appl. Bot. Food Qual. 2016, 89, $202-207$.

2. Durazzo, A.; D'Addezio, L.; Camilli, E.; Piccinelli, R.; Turrini, A.; Marletta, L.; Marconi, S.; Lucarini, M.; Lisciani, S.; Gabrielli, P.; et al. From Plant Compounds to Botanicals and Back: A Current Snapshot. Molecules 2018, 23, 1844. [CrossRef] [PubMed]

3. Montesano, D.; Montesano, D.; Giua, L.; Urbani, E.; Simonetti, M.S.; Blasi, F. A Simple HPLC-ELSD Method for Sugar Analysis in Goji Berry. J. Chem. 2016, 2016, 1-5. [CrossRef]

4. Blasi, F.; Montesano, D.; Simonetti, M.S.; Cossignani, L. A Simple and Rapid Extraction Method to Evaluate the Fatty Acid Composition and Nutritional Value of Goji Berry Lipid. Food Anal. Methods 2016, 10, 970-979. [CrossRef]

5. Cossignani, L.; Cossignani, L.; Blasi, F.; Perini, M.; Barbero, A.; Pianezze, S.; Montesano, D. Characterisation and geographical traceability of Italian goji berries. Food Chem. 2019, 275, 585-593. [CrossRef]

6. Cossignani, L.; Blasi, F.; Simonetti, M.S.; Montesano, D. Fatty Acids and Phytosterols to Discriminate Geographic Origin of Lycium barbarum Berry. Food Anal. Methods 2017, 11, 1180-1188. [CrossRef]

7. Pollini, L.; Rocchi, R.; Cossignani, L.; Mañes, J.; Compagnone, D.; Blasi, F. Phenol Profiling and Nutraceutical Potential of Lycium spp. Leaf Extracts Obtained with Ultrasound and Microwave Assisted Techniques. Antioxidants 2019, 8, 260. [CrossRef]

8. Mocan, A.; Zengin, G.; Simirgiotis, M.; Schafberg, M.; Mollica, A.; Vodnar, D.C.; Crişan, G.; Rohn, S. Functional constituents of wild and cultivated Goji (L. barbarum L.) leaves: Phytochemical characterization, biological profile, and computational studies. J. Enzym. Inhib. Med. Chem. 2017, 32, 153-168. [CrossRef] [PubMed]

9. Li, A.-N.; Li, S.; Zhang, Y.-J.; Xu, X.-R.; Chen, Y.-M.; Li, H.-B. Resources and Biological Activities of Natural Polyphenols. Nutrients 2014, 6, 6020-6047. [CrossRef] [PubMed]

10. Zheng, Y.; Yang, W.; Sun, W.; Chen, S.; Liu, D.; Kong, X.; Tian, J.; Ye, X. Inhibition of porcine pancreatic $\alpha$-amylase activity by chlorogenic acid. J. Funct. Foods 2020, 64, 103587. [CrossRef]

11. Gachons, C.P.D.; Breslin, P.A.S. Salivary Amylase: Digestion and Metabolic Syndrome. Curr. Diabetes Rep. 2016, 16, 102. [CrossRef]

12. Dall'Acqua, S.; Locatelli, M.; Stefanucci, A.; Macedonio, G.; Novellino, E.; Mirzaie, S.; Dvorácskó, S.; Carradori, S.; Brunetti, L.; Orlando, G.; et al. Chemical characterization, antioxidant properties, anti-inflammatory activity and enzyme inhibition of Ipomoea batatas L. leaf extracts. Int. J. Food Prop. 2017, 20, 1907-1919. [CrossRef]

13. Mahomoodally, M.F.; Mollica, A.; Stefanucci, A.; Aumeeruddy, M.Z.; Poorneeka, R.; Dall'Acqua, S. Volatile components, pharmacological profile, and computational studies of essential oil from Aegle marmelos (Bael) leaves: A functional approach. Ind. Crop Prod. 2018, 126, 13-21. [CrossRef]

14. Tomczyk, M.; Miłek, M.; Sidor, E.; Kapusta, I.; Litwińczuk, W.; Puchalski, C.; Dżugan, M. The Effect of Adding the Leaves and Fruits of Morus alba to Rape Honey on Its Antioxidant Properties, Polyphenolic Profile, and Amylase Activity. Molecules 2019, 25, 84. [CrossRef] [PubMed]

15. Abdelli, I.; Benariba, N.; Adjdir, S.; Fekhikher, Z.; Daoud, I.; Terki, M.; Benramdane, H.; Ghalem, S. In silico evaluation of phenolic compounds as inhibitors of A-amylase and A-glucosidase. J. Biomol. Struct. Dyn. 2020, 1-7. [CrossRef] [PubMed]

16. Demir, Y.; Durmaz, L.; Taslimi, P.; Gülçin, I. Antidiabetic properties of dietary phenolic compounds: Inhibition effects on $\alpha$-amylase, aldose reductase, and $\alpha$-glycosidase. Biotechnol. Appl. Biochem. 2019, 66, 781-786. [CrossRef] [PubMed]

17. Pagano, C.; Perioli, L.; Blasi, F.; Bastianini, M.; Chiesi, C.; Cossignani, L. Optimisation of phenol extraction from wine using layered double hydroxides and technological evaluation of the bioactive-rich powder. Int. J. Food Sci. Technol. 2017, 52, 2582-2588. [CrossRef]

18. Pollini, L.; Tringaniello, C.; Ianni, F.; Blasi, F.; Mañes, J.; Montesano, D. Impact of Ultrasound Extraction Parameters on the Antioxidant Properties of Moringa oleifera Leaves. Antioxidants 2020, 9, 277. [CrossRef] 
19. Urbani, E.; Blasi, F.; Simonetti, M.S.; Chiesi, C.; Cossignani, L. Investigation on secondary metabolite content and antioxidant activity of commercial saffron powder. Eur. Food Res. Technol. 2016, 242, 987-993. [CrossRef]

20. Rocchetti, G.; Blasi, F.; Montesano, D.; Ghisoni, S.; Marcotullio, M.C.; Sabatini, S.; Cossignani, L.; Lucini, L. Impact of conventional/non-conventional extraction methods on the untargeted phenolic profile of Moringa oleifera leaves. Food Res. Int. 2019, 115, 319-327. [CrossRef]

21. Wu, L.; Liu, Y.; Qin, Y.; Wang, L.; Wu, Z. HPLC-ESI-qTOF-MS/MS Characterization, Antioxidant Activities and Inhibitory Ability of Digestive Enzymes with Molecular Docking Analysis of Various Parts of Raspberry (Rubus ideaus L.). Antioxidants 2019, 8, 274. [CrossRef]

22. Berman, H.M.; Westbrook, J.; Feng, Z.; Gilliland, G.; Bhat, T.N.; Weissig, H.; Shindyalov, I.N.; Bourne, P.E. The Protein Data Bank. Nucleic Acids Res. 2000, 28, 235-242. [CrossRef]

23. Available online: http://pubchem.ncbi.nlm.nih.gov/ (accessed on 2 August 2020).

24. Halgren, T.A.; Murphy, R.B.; Friesner, R.A.; Beard, H.S.; Frye, L.L.; Pollard, W.T.; Banks, J.L. Glide: A New Approach for Rapid, Accurate Docking and Scoring. 2. Enrichment Factors in Database Screening. J. Med. Chem. 2004, 47, 1750-1759. [CrossRef] [PubMed]

25. Friesner, R.A.; Murphy, R.B.; Repasky, M.P.; Frye, L.L.; Greenwood, J.R.; Halgren, T.A.; Sanschagrin, P.C.; Mainz, D.T. Extra Precision Glide: Docking and Scoring Incorporating a Model of Hydrophobic Enclosure for Protein-Ligand Complexes. J. Med. Chem. 2006, 49, 6177-6196. [CrossRef] [PubMed]

26. Wishart, D.S.; Feunang, Y.D.; Guo, A.C.; Lo, E.J.; Marcu, A.; Grant, J.R.; Sajed, T.; Johnson, D.; Li, C.; Sayeeda, Z.; et al. DrugBank 5.0: A major update to the DrugBank database for 2018. Nucleic Acids Res. 2017, 46, D1074-D1082. [CrossRef] [PubMed]

27. Moscatello, S.; Frioni, T.; Blasi, F.; Proietti, S.; Pollini, L.; Verducci, G.; Rosati, A.; Walker, R.P.; Battistelli, A.; Cossignani, L.; et al. Changes in Absolute Contents of Compounds Affecting the Taste and Nutritional Properties of the Flesh of Three Plum Species Throughout Development. Foods 2019, 8, 486. [CrossRef] [PubMed]

28. Mocan, A.; Vlase, L.; Vodnar, D.C.; Bischin, C.; Hanganu, D.; Gheldiu, A.-M.; Oprean, R.; Silaghi-Dumitrescu, R.; Crişan, G. Polyphenolic Content, Antioxidant and Antimicrobial Activities of Lycium barbarum L. and Lycium chinense Mill. Leaves. Molecules 2014, 19, 10056-10073. [CrossRef]

29. Potterat, O. Goji (Lycium barbarum and L. chinense): Phytochemistry, Pharmacology and Safety in the Perspective of Traditional Uses and Recent Popularity. Planta Medica 2009, 76, 7-19. [CrossRef]

30. Qian, D.; Zhao, Y.; Yang, G.; Huang, L. Systematic Review of Chemical Constituents in the Genus Lycium (Solanaceae). Molecules 2017, 22, 911. [CrossRef]

31. Inbaraj, B.S.; Lu, H.; Kao, T.; Chen, B. Simultaneous determination of phenolic acids and flavonoids in Lycium barbarum Linnaeus by HPLC-DAD-ESI-MS. J. Pharm. Biomed. Anal. 2010, 51, 549-556. [CrossRef]

32. Mocan, A.; Vlase, L.; Raita, O.; Hanganu, D.; Păltinean, R.; Dezsi, Ș.; Gheldiu, A.M.; Oprean, R.; Crisan, G. Comparative studies on antioxidant activity and polyphenolic content of Lycium barbarum L. and Lycium chinense Mill. leaves. Pak. J. Pharm. Sci. 2015, 28, 1511-1515. [PubMed]

33. Min, S.W.; Han, J.S. Polyopes lancifolia Extract, a Potent $\alpha$-Glucosidase Inhibitor, Alleviates Postprandial Hyperglycemia in Diabetic Mice. Prev. Nutr. Food Sci. 2014, 19, 5-9. [CrossRef] [PubMed]

34. Funke, I.; Melzig, M.F. Effect of different phenolic compounds on $\alpha$-amylase activity: Screening by microplate-reader based kinetic assay. Pharmazie 2005, 60, 796-797. [PubMed]

35. Thummajitsakul, S.; Samaikam, S.; Tacha, S.; Silprasit, K. Study on FTIR spectroscopy, total phenolic content, antioxidant activity and anti-amylase activity of extracts and different tea forms of Garcinia schomburgkiana leaves. LWT 2020, 134, 110005. [CrossRef]

36. Mocan, A.; Moldovan, C.; Zengin, G.; Bender, O.; Locatelli, M.; Simirgiotis, M.J.; Atalay, A.; Vodnar, D.C.; Rohn, S.; Crișan, G. UHPLC-QTOF-MS analysis of bioactive constituents from two Romanian Goji (Lycium barbarum L.) berries cultivars and their antioxidant, enzyme inhibitory, and real-time cytotoxicological evaluation. Food Chem. Toxicol. 2018, 115, 414-424. [CrossRef] 
37. Sachan, A.K.; Rao, C.V.; Sachan, N.K. In vitro studies on the inhibition of $\alpha$-amylase and $\alpha$-glucosidase by hydro-ethanolic extract of Pluchea lanceolata, Alhagi pseudalhagi, Caesalpinia bonduc. Pharmacogn. Res. 2019, 11, 310. [CrossRef]

38. Jongkees, S.A.; Caner, S.; Tysoe, C.; Brayer, G.D.; Withers, S.G.; Suga, H. Rapid Discovery of Potent and Selective Glycosidase-Inhibiting De Novo Peptides. Cell Chem. Biol. 2017, 24, 381-390. [CrossRef]

Publisher's Note: MDPI stays neutral with regard to jurisdictional claims in published maps and institutional affiliations.

(C) 2020 by the authors. Licensee MDPI, Basel, Switzerland. This article is an open access article distributed under the terms and conditions of the Creative Commons Attribution (CC BY) license (http://creativecommons.org/licenses/by/4.0/). 